\title{
Trabalho interprofissional em saúde na construção do COAPES - relato de experiência de educação permanente de trabalhadores gestores
}

Grace Jacqueline Aquiles, Vanessa Denardi Antoniassi Baldissera, Lourdes Tome, Elizia Meire Zane, Leticia Dirlene Rozario Pimentel

\section{Resumo}

Os cursos de graduação em Saúde vêm sofrendo transformações nas últimas décadas, seja por força dos próprios fundamentos do Sistema Único de Saúde (SUS), das Diretrizes Curriculares Nacionais (DCN) ou da emergente necessidade da mudança nos desenhos assistenciais predominantes na Rede de Atenção em Saúde no Brasil. Um dos eixos de apoio ao modelo de reorientação na formação em saúde e nas práticas de atenção é o fortalecimento da integração entre ensino, serviços e comunidade no âmbito do SUS. Com esse entendimento, os Ministérios da Saúde e da Educação instituíram, em 2015, diretrizes para que seja firmado o Contrato Organizativo de Ação Pública de Ensino-Saúde - COAPES. Esse contrato constitui-se em um dispositivo da Política Nacional de Educação Permanente ofertado aos atores do Sistema Único de Saúde (gestores, trabalhadores e usuários) e da Educação Superior da área da saúde (gestores, docentes e estudantes) para promover processos participativos de construção da formação e desenvolvimento profissional no SUS e para o SUS (BRASIL, 2016). O COAPES tem como pressuposto favorecer o desenvolvimento de processos de diálogos e pactuações locais que envolvem todos os atores bem como se constituir em ferramenta e recurso na construção prática da integração ensino-serviço-comunidade, tendo a Educação Permanente em Saúde (EPS) como principal referencial ético-político (BRASIL, 2016). Apesar das iniciativas formais envolvendo os Ministérios da Educação e Saúde na última década, o modelo de educação em saúde no Brasil é ainda caracterizado pelo predomínio de disciplinas isoladas, valorização do procedimento técnico, construção de ideais de corporações profissionais que acabam por favorecer a fragmentação do cuidado, dos saberes e das práticas e, por fim reforça $o$ tradicional modelo biomédico. Também temos a compreensão que quando se pretende contribuir com a articulação dos diversos interesses e processos presentes no cotidiano do SUS, essa construção não se configura em algo simples, nem isento de disputas e conflitos, no entanto enquanto uma possibilidade que vai ao encontro das necessidades já presentes na relação entre instituições de ensino, serviços e comunidade, vale o esforço e o empreendimento de ações que superem as dificuldades. Nesse trabalho temos por objetivo relatar o processo de formação no trabalho de um grupo gestor municipal para a elaboração de uma proposta de COAPES em um município de médio porte do noroeste paranaense. Desde 2016 há no município um movimento de diálogo entre os gestores estadual e municipal, apoiadores do CONASEMS e instituições de ensino superior e representantes de residências médica e multiprofissional em saúde na perspectiva do desenvolvimento de consensos em torno de uma proposta para o município que articule a integração do ensino, serviço e comunidade. No primeiro semestre de 2017 o gestor municipal em reunião com todos os atores envolvidos, solicitou a elaboração de uma proposta de COAPES estabelecido o prazo de um ano. Com dificuldades conceituais dentro do próprio grupo gestor da Secretaria Municipal de Saúde (SMS) do município, e as implicações que esse obstáculo vinha causando no andamento da construção da proposta, a condutora do processo, responsável pelo Centro de Capacitação da SMS, convidou duas docentes de uma Universidade Pública do Município para uma assessoria no grupo, dentro de uma proposta de educação permanente. Foram então agendados sete encontros semanais no segundo semestre desse ano, com um grupo aqui denominado de gestor pois constituía-se de trabalhadores de diversas profissões da saúde em cargos de coordenações na 
SMS. Os encontros aconteceram na própria SMS, às terças-feiras e foram fundamentados em metodologias ativas. Os temas foram construídos a partir das necessidades do grupo com relação ao alcance da imagem objetivo que era a proposta do COAPES. A interprofissionalidade foi o eixo condutor das discussões, que eram direcionadas à busca de soluções coletivas com ênfase no modelo de atenção desejado pelo grupo e na consciência da necessidade de superação das discussões corporativas. No primeiro encontro optou-se por uma roda de conversa com o grupo sobre as expectativas de cada um a respeiro dos encontros, construção de uma agenda de trabalho e na sequência houve uma apresentação teórica a respeito de alguns conceitos chave para as discussões. Como era de se esperar, houve manifestações de desconforto, inclusive com observações a cerca do idealismo que rege alguns trabalhos da academia no SUS. Procurou-se nesse momento acolher as falas e explicitar as intencionalidades ali alocadas. A partir dos apontamentos do grupo e suas expectativas em relação a um trabalho mais "prático" por parte das docentes para o grupo, no segundo encontro e subsequentes o trabalho foi realizado a partir de uma matriz constituída por eixos de potencialidades existentes (que bom que...); fragilidades existentes (que pena que...); sugestões (e se....). A Matriz orientou a discussão do artigo 4o da Portaria Interministerial $\mathrm{n}^{\mathbf{0}} 1.127$, de 04 de agosto de 2015. A partir das discussões surgiram outros pontos, novas necessidades de teorização, novas reflexões, novas abordagens e assim o grupo foi trabalhando num processo de reflexão-ação em suas sucessivas aproximações com o objeto. $\mathrm{O}$ maior nó crítico encontrado pelo grupo foi a concepção e atribuições da preceptoria em saúde. Os encontros e apresentaram como principal resultado a construção de um consenso conceitual em torno de questões que permeiam a construção de um COAPES. Ainda como resultado desses encontros, elaborou-se a proposta de um Fórum Interprofissional de Integração Ensino-serviçocomunidade a ocorrer no início de 2018, para ampliação do debate entre os atores do município. Concluimos que caminhos que abram o espaço do diálogo entre todos os envolvidos na formação e na atenção em saúde, que proporcionem novas possibilidades de se pensar o processo de trabalho em saúde são sempre oportunidades vivas de mudanças, potencializadoras de transformações desejadas na educação e nos desenhos assistenciais. Acreditamos que a corresponsabilidade de usuários, gestores, trabalhadores, professores e estudantes com a saúde da população, em cada território, deve nortear os processos formativos e de desenvolvimento no SUS, proporcionando um permanente processo de ensino e aprendizagem articulado às práticas reais nos serviços. Apesar do caminho de integração vir sendo percorrido há algum tempo no território desse município, e já ter acumulado experiências de ações articuladas, envolvendo diferentes atores, serviços e instituições, que viabilizam as aproximações do mundo da formação com o mundo do trabalho, acreditamos que esse momento formados do grupo gestor municipal, neste contexto, favoreceu o balizamento conceitual e processo de pactuações e contratualizações futuras que permitirão avançar a partir do atual estado em que se encontra a integração ensino-serviço-comunidade nesse município.

Descritores: Atenção básica, Educação permanente em saúde, Formação em saúde, Trabalho interprofissional 